\title{
Relationship between Academic Self-Concept and Students' Performance among School Age Children
}

\author{
Hanan Ebrahim Abd El Aziz Rady ${ }^{1}$, Shabana Kabeer², Mona T. El-Nady ${ }^{1}$, \\ ${ }^{1}$ Department of Psychiatric/Mental Health Nursing, Faculty of Nursing, Cairo University, Cairo, Egypt \\ ${ }^{2}$ Department of Health Informatics \& Information Management, Faculty of Public Health \& Health Informatics, University of Hail, Hail, \\ Kingdom of Saudi Arabia
}

\author{
Email address: \\ monatalat2001@yahoo.com (M. T. El-Nady) \\ *Corresponding author
}

\section{To cite this article:}

Hanan Ebrahim Abd El Aziz Rady, Shabana Kabeer, Mona T. El-Nady. Relationship between Academic Self-Concept and Students' Performance among School Age Children. American Journal of Nursing Science. Vol. 5, No. 6, 2016, pp. 295-302. doi: 10.11648/j.ajns.20160506.19

Received: December 5, 2016; Accepted: December 19, 2016; Published: February 10, 2017

\begin{abstract}
Students' academic performance plays an important role in producing the best quality graduates who will become great leader and manpower for the country thus responsible for the country economic and social development. This article sought to study the relationship between academic self-concept and students' performance among school age children. A descriptive correlational design was utilized in this study. This article was carried out in freedom school for basic education boys and girls at Cairo governorate. A purposive sample was composed of 182 school age children and their teachers. Tools of data collection consisted of three parts: 1-Structured Questionnaire: it consisted of students' socio-demographic characteristics including personal data; such as gender, age, and family history, family size. 2- Academic Self-Concept Scale, 3-Academic Performance Rating Scale. Results indicated that there was a significant statistical relationship between academic self-concept and students' performance among school age children. This finding implies that there was a wide gap in how males develop their self-concept as compared with female students. The relationship between gender and academic performance was investigated. It was concluded that students' academic self-concept can affect their performance. The students with high academic achievement receive reward and have more opportunities in future. The researchers recommended implementing psycho-educational program in formal and informal curriculum for parents, teachers to provide a chance for students express themselves and developing their self-esteem and self-confidence.
\end{abstract}

Keywords: Academic Self-Concept, Students' Performance, School Age Children's

\section{Introduction}

\subsection{Background of the Study}

Self-concept is the core of human personality. It refers to the totality of people's perception about their physical, social and academic competence. It is the set of perceptions that the person has about himself, the set of characteristics, attributes, qualities, deficiencies, capacities limits, values and relationships that the subject knows to be descriptive of him [1].

Academic Self-Concept (ASC) refers to "the personal beliefs someone develops about their academic abilities or skills". A person's ASC develops with mental and physical growth and begins to develop at early childhood. Parenting styles and early educators have an influence on Academic self-concept [2]. "Self-concept is an important construct in development psychology and education and had multidimensional construct, one general facet and several specific facets, one of which is 'academic self-concept" [3; 4].

Academic self-concept and academic performance directly affect each other. Academic self-concept for example: how one understands himself as an individual who has a set of unique or special characteristics. "Their beliefs and opinions 
are based on their sensitivity and self awareness about their strength and weakness. Establishment of one's Academic self-concepts is built by the person's nature, maturity, and his natural surroundings". The important people that buildup of Academic self-concepts are parents, adults, peers and one's own self $[5 ; 6]$.

Teachers show an important role in developing the academic self-concept among school age children. When teachers acted something on a child without respect, he might have a negative effect such as accepting himself as weak. Therefore, there is an association between academic selfconcept and academic performance. Individuals, who have high academic performance are characterized by feeling more responsibility in school and seldom violate the rules and regulations [7].

For developing the student's positive academic selfconcept, parents should provide a pleasant atmosphere at home with full of happiness and to fulfill the desires of children. A helpful learning environment by teachers can fulfill the psychological needs of the students. Parent, school, peers, teachers, media, society, and culture all of these influence on the child's academic self-concept. School and teachers have a straight effect on child's feelings, inspirations and attitudes and on their academic achievement [8].

Academic self-concept can be classified into two major types that are positive academic self-concept and negative academic self-concept. Positive academic self-concept is concerned, that person has confident and sure of himself, good interests, objective and not too sensitive. This individual may accept the criticism from others and may able to express their views and opinions. On differing point, individual who has negative academic self-concept has too subjective nature. "Academic achievement or academic performance is the outcome of education" [9;10]. Academic self-concept influences not only a student's academic performance but also his or her effort, engagement, and persistence in classroom activities; intrinsic motivation; helpseeking behavior and course selection [11].

Furthermore, academic self-concept has a significant consequence on academic performance and vice versa and that such a reciprocal relation is valid cross-culturally. This positive relation was further demonstrated by the significant relation between self-concept and academic achievement [12; 13]. According to [14] \& [15] "self-efficacy refers to judgments of a person's capabilities, and their ability to carry out the actions needed to succeed in a task. It is one of the strongest factors predicting performance in domains as diverse as sports, business, and education". In academic settings, the students with high academic self-concept were more admired, supportive, determined in class activities with lower nervousness and higher expectations of future success. Boys possess advanced academic self-concept as compared to girls. The academic self-perception of science courses is higher in boys as compared to girls. Academic self-concept starts in early school and remains till mature age [16].

According to, [17] "academic performance is the measured ability and performance level of a learner in a school, subject or particular skills". Therefore academic performance has to do with a learner's scholastic ability and attainment, as regards his or her work and this is often measured through tests, exams, course works and assignments.

Furthermore, "academic performance is the outcome of education the extent to which a student, teacher or institution has achieved their educational goals. It is commonly measured by examinations or continuous assessment but there is no general agreement on how it is best tested or which aspect is most important procedural knowledge" [18]. A study conducted by Zimmerman [19] revealed that, academic performance can be defined as self-regulated learning, including excellence in sports, arts, culture, behavior, confidence, and communication skills, and it shows how learners control their emotion, feelings, and actions in order to academically achieve. Academic self-concept and students' performance are related. Accordingly, attempts should be made to enhance students' academic self-concept during their education that will enhance students' performance. These findings can be helpful to teachers, authorities, nursing teams and nursing managers. Moreover, to enable students, teachers, nurses need to help develop the academic self-concept of their students, dedicate time for private conversation with their students, listen to their worries, appreciate students' real attitude toward the education process and correct it as best as they can, and most importantly, introduce the nursing and nurses' capacities to the society.

\subsection{Statement of Problem}

Academic experiences of success or failure significantly affect the students' self-concept and their self-image, this being enlightened by the role of evaluation by significant others, or by the theory of social comparison. Therefore, it would be possible to improve levels of school performance by previously optimizing levels of self-concept and levels of perceived competence [20]. Academic self-concept and highacademic self-efficacy are emotional strengths seemed to play an important roles in enabling academic success despite their special disabilities. Perceived high-academic selfconcept derived from two sources: students' focus on strengths and achievement in their learning and in their area of interest. Once a positive effect, the perceived high competence high motivation, academic success, highacademic self-concept, is established it will continue to enable students' positive emotional and behavioral outcomes in their learning. Hence, it is important to emphasize students' assets and goods more than the mediation of their weaknesses in implementing supporting strategies. The current study will help psychiatric nurses to provide adequate and sufficient attention to students' self-esteem and selfconcept and to add to parents and teachers body of knowledge and give more recognition to meet students' needs and to achieve best developmental outcomes. When students' strengths are emphasized and their self-confidence is boosted, they are motivated to put more effort into learning, and they also will be confident in their ability, that 
is why an attempt has been made to study the relationship between academic self-concept and students' performance among school age children.

\subsection{Aim}

This article aimed to study the relationship between academic self-concept and students' performance among school age children.

\subsection{Research Questions}

- Is there a relationship between students' gender and their performance?

- Is there a relationship between students' gender and their academic self-concept?

- Is there a relationship between academic self-concept and students' performance?

\section{Methodology}

\subsection{Research Design}

A descriptive correlation design was utilized in this study.

\subsection{Subjects}

A purposive sample was composed of 182 school age children from basic education and their teachers. The teachers were facilitating the data collection process.

Inclusion Criteria:

- Both gender.

- Agree to join the study.

- Primary and preparatory school age students ranged between 9-15 years old.

\subsection{Setting}

The study was carried out in freedom school for basic education boys and girls at Cairo governorate, Egypt.

\subsection{Tools of Data Collection Consist of Three Parts}

1 Structured questionnaire was established by the researchers.

It composed of demographic characteristics; it was designed to collect personal data about students such as age, gender and family history.

2 Academic Self-Concept Scale (ASCS) was utilized to measure academic self-concept; it was designed by [21]. It consisted of three components namely academic, physical and social self-concept having 60 items. 50\% statements $47-48$ were negatively phrased. The scale used in this study was translated into Arabic language. Responses were delimitated to 4-point scale and the number of items were reduced to 20 because only academic was added as the study was restricted to only academic component. Physical and social components were eliminated. The reliability of modified version of SDQIII, test-retest method was used because it was considered by the measurement experts to be the best method for the purpose. Reliability of the tool was performed to confirm consistency of the tool and was calculated statistically. The internal consistency was measured to identify the extent to which the items of the tool measure the same concept and correlate with each other. Reliability of the study's tool was done by Cronbach Alpha test. The reliability coefficient obtained through test-retest method was 0.89 which is quite reasonable measuring each specific dimension of self-concept had adequate concordance; Kendall's-tau-b was applied. While using this technique, positive and negative statements were also taken into consideration. Back translation was done by two researchers.

3 Academic Performance Rating Scale (APRS). This scale was established by [22]. It was used to measure teachers' perception of academic performance for children. It was designed to be used as part of a more comprehensive assessment battery. It consisted of 19 items classified into 3 subscales: Academic Success (7 items), Impulse Control (3 items), and Academic Productivity ( 9 items). Items rated on a scale from 1 ('never' or 'poor') to 6 (very often' or 'excellent). The tools were submitted to a five experts in specialty to confirm tool validity. Some modifications on the tools were done according to the judgment in relation to appropriateness of the content and sequence accuracy of the items.

\subsection{Pilot Study}

It was done on $10 \%$ of the study subjects to test the clarity, validity and reliability of the study tools. The subjects involved in the pilot study were excluded from the study and the needed corrections were done. Pilot study showed that the average length of the time needed to complete the structured questionnaire schedule was approximately 30-45 minutes with each student.

\subsection{Ethical Consideration}

Informed consent was granted from each participant, then brief description of the purpose of the study and the type of questionnaires required to be filled was given to each participant. Anonymity and confidentiality were also assured through coding the data.

\subsection{Field Work}

An official Permission was attained from the school director and teachers. Researchers started data collection by introducing themselves to school age students and explained aim of the study and the content of the tools to establish an initial rapport between students and researcher, all questions were answered and detailed explanation was given to obtain their acceptance and cooperation during conducted the interview sessions. Data collected through interview with students using different tools. The average time needed for completion the interview was around 30-45 minutes. Data 
collection was done in a period of four month from the beginning of February to the end of May 2015. The researchers were accessible for 2 days/week, from 9.00 A.m. to 12,00 P.m.

\subsection{Statistical Analysis}

The researchers used SPSS Version 17.1 program and Excel Statistical Package in order to ensure speed and accuracy in the statistical treatment. Frequency: Calculates how often values occur within a range of values. The data will be collated and tabulated to determine frequency of responses.

(1) Percentage: This was used as a descriptive statistics to denote the proportion contributed by a part in a whole.

(2) Mean: The mean is the arithmetic average of a set of values, or distribution; however, for skewed distributions, the mean is not necessarily the same as the middle value (median), or the most likely (mode).

(3) Pearson Correlation: Pearson Product moment Correlation Coefficient was used to compute the relationship between the socio-demographic profile and dependent variable.

\section{Results}

Table 1 showed that, the percentage of males were $(51.60 \%)$ and females were $(48.40 \%) .16 .40 \%$ of the subjects' age range was $10>12$ years. More than half of the participants were of $12>14$ years $(56.50 \%)$. While $27.10 \%$ of them were more than 14 years old. Regarding family information/parents status, majority of them had both father and mother $(95.60 \%)$. While children from divorced families were $(1.60 \%)$. Children had one parent were $(1.10 \%)$ of the subjects. Children from separated families were $1.60 \%$. As far as numbers of family members were concerned, more than three quarters of them had $4-<8$ members in the family $(75.80 \%)$. while $23.60 \%$ of them had $2-<4$ family members. while $>8$ family members were $0.50 \%$.

Table 1. Distribution of study subjects according to their socio-demographic characteristics $(N=182)$.

\begin{tabular}{lll}
\hline $\begin{array}{l}\text { Students Demographic } \\
\text { Characteristics }\end{array}$ & Frequency N & (Percentage) (\%) \\
\hline Gender & & \\
Male & 94 & 51.60 \\
Female & 88 & 48.40 \\
Total & 182 & 100 \\
Age & & \\
$10>12$ y & 30 & 16.40 \\
$12>14 y$ & 102 & 56.50 \\
More than 14 y & 50 & 27.10 \\
Total & 182 & 100 \\
Parents Status & & \\
Together & 174 & 95.60 \\
Separated or Divorced & 6 & 3.20 \\
Widowed & 2 & 1.10 \\
Total & 182 & 100 \\
Number of Family Members & & \\
2-<4 & 43 & 23.60 \\
$4-<8$ & 138 & 75.80 \\
$>8$ & 1 & 0.50 \\
Total & 182 & 100 \\
\hline
\end{tabular}

Table 2 represented that, the high mean scores for items response in relation to academic self concept was "I get good marks in most academic subjects" (3.43\%) followed by" I am good at expressing myself "(3.32\%) respectively, while the lowest means scores for items response in relation to academic self concept was In school, "I have more trouble learning to read than most other students" (1.58\%).

Table 2. Academic self-concept of school age children $(n=182)$.

\begin{tabular}{|c|c|c|c|}
\hline S\# & Indicators & Mean & SD \\
\hline 1. & I have trouble expressing myself when trying to write something. & 1.92 & 0.897 \\
\hline 2. & I can write effectively. & 3.15 & 0.857 \\
\hline 3. & I have a poor vocabulary. & 1.97 & 1.01 \\
\hline 4. & I am an avid reader. & 3.07 & 1.065 \\
\hline 5. & I do not do well on tests that require a lot of verbal reasoning ability & 1.99 & 1.072 \\
\hline 6. & Relative to most people, my verbal skills are quite good & 3.14 & 0.97 \\
\hline 7. & I often have to read things several times before I understand them. & 3.31 & 1.016 \\
\hline 8. & I am good at expressing myself. & 3.32 & 0.86 \\
\hline 9. & In school I have more trouble learning to read than most other students. & 1.58 & 0.874 \\
\hline 10. & I have a good reading comprehension. & 3.26 & 0.95 \\
\hline 11. & I enjoy doing work for most academic subjects. & 3.05 & 1.01 \\
\hline 12. & I hate studying for many academic subjects. & 2.3 & 1.03 \\
\hline 13. & I like most academic subjects. & 3.14 & 0.974 \\
\hline 14. & I have trouble with most academic subjects. & 2.23 & 1.079 \\
\hline 15. & I am good at most academic subjects. & 3.3 & 0.879 \\
\hline 16. & I am not particularly interested in most academic subjects. & 1.91 & 1.026 \\
\hline 17. & I learn quickly in most academic subjects. & 3.14 & 0.923 \\
\hline 18. & I hate most academic subjects. & 2.19 & 1.06 \\
\hline 19. & I get good marks in most academic subjects. & 3.43 & 0.817 \\
\hline 20. & I could never achieve academic honors, even if I worked harder. & 1.83 & 1.035 \\
\hline
\end{tabular}


Table 3 indicated that, the high mean scores for items response in relation to students' academic performance was "How frequently does the student accurately follow teacher instructions and/ or class discussion during small-group (e.g., reading group) instruction" (4.11\%) followed by "How frequently does the student accurately follow teacher instructions and/ or class discussion during large group (e.g., whole class) instruction" (4.04\%). respectively. While the lowest mean scores for items response in relation to students academic performance were "How often does the child appear withdrawn or tend to lack and emotional response in a social situation" (2.27\%) followed by "How frequently does this child have difficulty recalling material from a previous day's lessons " (2.4\%) respectively.

Table 3. Students' performance as rated by their teachers $(n=182)$.

\begin{tabular}{|c|c|c|c|}
\hline S\# & Indicators & Mean & SD \\
\hline 1. & Estimate the percentage of written math work completed (regardless of accuracy) relative to classmates. & 3.69 & 1.083 \\
\hline 2. & Estimate the percentage of written Language Arts work completed (regardless of accuracy) relative to classmates. & 3.78 & 1.02 \\
\hline 3. & Estimate the accuracy of completed written Math work (i.e., percent of correct work done). & 3.64 & 0.957 \\
\hline 4. & Estimate the accuracy of completed written language Arts Work (i.e., percent correct of work done). & 3.58 & 1.097 \\
\hline 5. & How consistent has the quality of the child's academic work been over the past week? & 3.89 & 0.959 \\
\hline 6. & $\begin{array}{l}\text { How frequently does the student accurately follow teacher instructions and/ or class discussion during large group (eg, whole } \\
\text { class) instruction? }\end{array}$ & 4.04 & 0.878 \\
\hline 7. & $\begin{array}{l}\text { How frequently does the student accurately follow teacher instructions and/ or class discussion during small-group (e.g., reading } \\
\text { group) instruction? }\end{array}$ & 4.11 & 0.91 \\
\hline 8. & How quickly does this child learn new material learn new material (i.e., pick up novel concepts)? & 3.78 & 0.902 \\
\hline 9. & What is the quality or neatness of this child's handwriting? & 3.73 & 1.074 \\
\hline 10. & What is the quality of this child's reading skills? & 3.76 & 0.981 \\
\hline 11. & What is the quality of this child's speaking skills? & 3.71 & 1.1 \\
\hline 12. & How often does the child complete written work in a careless, hasty fashion? & 2.76 & 1.11 \\
\hline 13. & How frequently does the child take more time to complete work than his/ her classmates? & 2.93 & 0.963 \\
\hline 14. & How often is the child able to pay attention without you prompting him/ her? & 3.38 & 1.134 \\
\hline 15. & How frequently does this child require your assistance to accurately complete his/ her academic work? & 3 & 0.977 \\
\hline 16. & How often does the child begin written work prior to understanding the directions? & 2.84 & 0.952 \\
\hline 17. & How frequently does this child have difficulty recalling material from a previous day's lessons? & 2.4 & 0.809 \\
\hline 18. & How often does the child appear to be staring excessively or 'spaced out"? & 2.58 & 0.892 \\
\hline 19. & How often does the child appear withdrawn or tend to lack and emotional response in a social situation? & 2.27 & 1.053 \\
\hline \multicolumn{4}{|c|}{ GRAND MEAN SCORE: 3.36} \\
\hline
\end{tabular}

Table 4 revealed that the correlation between academic self-concept and students' academic performance. As can be gleaned from the table, the Pearson correlations statistic is.256 which is descriptively interpreted as having "low correlations" and supported by a significant p-value of.045 respectively. It implies that the students' self-concept was positively related to their academic achievement.

Table 4. Relationship between academic self-concept and students' performance among school age children ( $n=182)$.

\begin{tabular}{l|lll}
\hline Variables & r & p-value & Description \\
\hline Academic Self-Concept VS Academic Performance & $.256^{*}$ & 0.045 & low correlations \\
\hline
\end{tabular}

* Significance level at $\mathrm{P}<0.05$

Table 5 showed that, gender was significantly related to self-concept $(r=0.3$, p-value $=.00)$ however, the description of similarities was regarded as "low correlations". Another pairing of variables that had a significant relationship was age and self-concept $(\mathrm{r}=-.44, \mathrm{p}$-value $=.00)$, and verbally interpreted as having "negatively moderate correlations". This finding implies that there was a wide gap in how males develop their self-concept when compared with female students. All other variables entered into correlations did not bear any significant findings at all.

Table 5. Correlations between socio-demographic characteristics \& academic self-concept of school age children ( $n=182$ ).

\begin{tabular}{llll}
\hline Variables & r & p-value & Analysis \\
\hline Gender VS Academic Self-Concept & 0.3 & $.00^{* *}$ & Low correlations \\
Age VS Academic Self Concept & -0.44 & $.00^{* *}$ & Negative moderate correlations \\
Family Size VS Academic Self-Concept & -0.08 & 0.269 & Negative very low correlations \\
Family History VS Academic Self-Concept & 0.04 & 0.59 & Very low correlations \\
\hline
\end{tabular}

*Significance level at $\mathrm{P}<0.05$

Table 6 delineated the relationship of gender to students' performance. As shown, the correlation coefficient of 0.051 or interpreted as having "very low correlations" and supported by a p-value of.418 inferred that gender was not linearly related to students' performance of school age students. It further entailed that, gender was not a significant factor to consider when measuring the academic performance of the students. Regardless of students' 
gender, they are equal footing in terms of chances to succeed in their scholastic endeavors.

Table 6. Relationship between gender and students' performance of school age children $(n=182)$.

\begin{tabular}{llll}
\hline Description & p-value & $\mathbf{r}$ & Variables \\
\hline low correlations & 0.418 & 0.051 & $\begin{array}{l}\text { Gender VS Academic } \\
\text { Performance }\end{array}$ \\
\hline
\end{tabular}

*Significance level at $\mathrm{P}<0.05$

\section{Discussion}

Regarding "academic self-concept", the mean scores showed that most of the students responded in statement, "I take good marks in most of the subjects" I am good at expressing myself and "I often have to read things several times before I understand them". This means that the participants had good academic self-concept but at the same time they have difficulty in concentration and understanding. The teacher's evaluation for the students showed that, the highest mean score for performance and the students accurately followed the teacher instructions during large and small groups. It showed that the good performance for the students.

A study was done by [4] pointed out that "by age 11 children assess their academic abilities by comparing themselves to their peers". These social comparisons were also referred to as self-estimates. In the same context, some researchers suggested that, to raise academic self-concept, parents and teachers needed to provide children with specific feedback that focuses on their particular skills or abilities. On different point of view [14] stated that, learning opportunities should be conducted in groups (both mixed-ability and likeability) that downplay social comparison, as too much of either type of grouping can have adverse effects on children's academic self-concept and the way they view themselves in relation to their peers.

Concerning relationship between academic self-concept and academic achievement the results showed that a significant association was found between them which are descriptively interpreted as having "low correlations" and supported by a significant p-value of .045 respectively. Almost the same result was found by $[23 ; 24]$ who found that, "students who had higher academic achievement were at an advantage in terms of positive outcomes such as joy, pride, and happiness having higher academic achievement had been associated with positive characteristics, including self-esteem, self-efficacy, and motivation. Conversely, lower academic achievement was linked to low levels of particular achievement goals".

Moreover, a study was done by $[11 ; 25]$ added that, "the adverse impact of repeated academic failure can threaten a student's academic self- concept and general self-worth. As a result, a student may develop a need to protect both their private and public sense of perceived academic competence or self-worth from failure. The need for self-worth protection can result in the development of maladaptive defensive strategies that include defensive pessimism, selfhandicapping and self-worth protection".

In the same line, a study was done by [26] delineated that, there were many factors affecting academic performance a part from academic self concept. There is not a single factor behind the relationship between academic self concept and academic performance. May be the academic concept is good but cognitive ability was low. Cognitive ability was essential in predicting academic outcomes [26] pointed out that, not only cognitive but studies showed that personality was very important in predicting academic achievement.

From another viewpoint $[27 ; 28]$ highlighted that, "there was relationship between personality type and academic achievement of secondary school students with regard to some categories of variables. This confirms the common belief of the educationists that personality alone cannot decide the achievement of students, suggesting that, there could be some other factors, and this beckons the teachers and parents to explore and find out those influencing factors and thereby helping the students in their academic advancement".

On the other contrary, a study done by [29] pointed out that the types of school whether it is high or low achieving also have a significant impact on student's achievement and self-concept. According to [30] "academic self-concept and academic performance are different in different types of schools which showed that there was a difference between high and low facility schools factors such as location of the school, method of teaching, extracurricular activities, relationship between students and teachers all play an important role".

In relation to academic performance and students' gender, a significant statistical low correlation was found between both variables. It further entailed that, gender was not a significant factor to consider when measuring the academic achievements of the students. According to [31] gender does not influence self-concept and self concept does not influence academic achievement in any case. In contrast a study done by [32] suggested that there may be important differences between genders in the way they define their academic self. According to [33] emphasized that, there was a significant difference in the academic self-concept between male and female students.

In this respect, most studies showed that, on average, girls did better in school than boys. Girls got higher grades and completed high school at a higher rate compared to boys' standardized achievement tests also show that females were better at spelling and performed better on tests of literacy, writing, and general knowledge [7].

A study was done by [34] found that, scholastic achievement is the attained level at which the student is functioning in school tasks as measured by school marks and grades earned. There is increasing recognition within developmental, educational and sociological theories that the performance of both boys and girls in different subjects is different.

According to [1] "the students with higher academic effort 
had high academic achievement. It means if students study hard with much effort they can achieve their academic goals; the higher the efforts the higher the academic achievement. The study also concluded that females had a relatively higher mean score for academic effort as compared to males which leaded to higher academic achievement".

All these results are due to the fact that girls nurtured more or less similarly in all the families and they mature early physically and psychologically. Therefore there is every chance to find individual differences among girls to a minimum extent, correspondingly now a day's mass media had given more importance to develop independency among girls. Therefore girls are encouraged highly to supersede boys in their academic performance by exploration and commitment. Moreover, some studies have shown that, the amount of social support from the school and outside contributors like family, friends and mentors can make a huge impact on a student's success. Support such as emotional, academic, and financial are tremendous factors in the success of school age student. On other contrary, there are a number of health related factors that can contribute to a student's academic performance and therefore have an effect on his or her GPA. The amount of exercise, nutritional routine also the amount of social support the student perceives all can contribute to how a student academically performs.

The results showed that there was a statistically negative correlation between students' age, gender \& academic selfconcept. Many studies supported the existence of a significant decline in students' academic self-concept from early to mid-adolescence [36]. A study done by $[35 ; 20]$ revealed that academic self-concept starts developing from ages 3 to 5 due to influence from parents and early educators whereas by age 10 or 11 , children assess their academic abilities by comparing themselves to their peers.

Results highlighted that a statistically significant negative correlation was found between self-concept and family size. Almost the same result was found by [3] who pointed out that birth order and sibling relations may also be consequential for children's self-concept. On the basis of both reflected appraisals and social comparisons, we would expect first-borns to have higher self-concept than later-born children. The greater attention and encouragement from parents should contribute to first-borns' greater sense of worth and importance; and first-borns' typically greater power and competence compared with younger siblings should result in more favorable social comparisons.

However, "individuals with limited pro-social behaviors and high frequency or intensity of problem behaviors tend to display a higher incidence of violent behavior, truancy, depression, alcohol use, drug use, rejection by their peers, lower academic motivation, lower standardized test scores and increased academic failure" [37].

\section{Conclusion}

Students' academic self-concept can affect their performance. Gender was not linearly related to academic performance of school age students. It further entailed that, gender was not a significant factor to consider when measuring the academic performance of the students. A significant negative statistical correlation was found between students' age and their academic self-concept.

\section{Recommendations}

- Another longitudinal study could be carried out with cohort of students from different levels to investigate the relation between their academic performance and risk factors.

- Future studies are needed to provide attention to selfconcept and self-esteem among school age students also their teachers, nurses and parents should be offered methodological guidance in order to work on this throughout the educational process.

- Based on results, it is suggested to implement psychoeducational program in formal and informal curriculum for parents, teachers to provide a chance for students express themselves and develop their self-esteem and self-confidence.

- Future studies are needed to investigate the relationship among gender and associated factors.

\section{References}

[1] Zahra, A. (2010). Relationship between Self-concept and Academic Achievement of Female Bachelor Degree students. $\mathrm{PhD}$ thesis, PMAS- Arid Agriculture University, Rawalpindi.

[2] Benner, A. D. \& Mistry, R. S. (2007). Congruence of mother and teacher educational expectations and low-income youth's academic competence. Journal of Educational Psychology, 99 (1). 140-153. doi:10.1037/0022-0663.99.1.140.

[3] Trautwein, U., Ludtke, O., Nagy, G. \& Marsh, H. W. (2009). Within-School Social Comparisons: How students perceive the standing of their class predicts academic self-concept. Journal of Educational Psychology, 101 (4). 853-866.

[4] Marsh, H. W. \& Martin, A. J. (2011). Academic self-concept and academic achievement: Relations and causal ordering. British Journal of Educational Psychology, 81 (1): 59-77.

[5] Azizi, Y. (2009). Relationship between self-concepts and personality and students' academic performance in selected secondary schools. European Journal of Social SciencesVolume 11, Number 2.

[6] Wilson, E. H. (2009). A Model of Academic Self-Concept: Perceived difficulty, social comparison, and achievement among academically accelerated secondary school students university of Connecticut, Retrieved from

http://www.gifted.uconn.edu/siegle/dissertations/hope\%20wils on.pdf.

[7] Zembar, M. J. \& Blume, L. B. (2011). Gender and academic achievement updated- Pearson Allyn Bacon Prentice Hall on Jan 26.

[8] Matsumoto, D. \& Juang, L. (2008). Culture and psychology (4th ed.). Belmont, CA: Wadsworth/Cengage Learning. 
[9] Strage, A. \& Brandt, T. S. (1999). Authoritative parenting and college students' academic adjustment and success. Journal of Educational Psychology, 91, 146-156.

[10] Hughes, J. \& Kwok, O. (2007). Influence of student-teacher and parent-teacher relationships on lower achieving readers' engagement and achievement in the primary grades. Journal of Educational Psychology, 99 (1), 39-51.

[11] Bong, M. \& Skaalvik, E. M. (2003): Academic self-concept and self-efficacy: How different are they really? Educational Psychology Review, 15, 1-40.

[12] Valentine, J. C., DuBois, D. L. \& Cooper, H. (2004). The relation between self-beliefs and academic achievement: A meta-analytic review. Educational Psychologist, 39, 111-133.

[13] Marsh, H. W. \& Seaton, M. (2012). Academic self-concept. In J. Hattie \& E. M. Anderman (Eds.), International guide to student achievement (pp. 62-62). New York, NY: Routledge.

[14] Myers, D. G. (2009). Social psychology (10th ed.). New York: McGraw-Hill Higher Education.

[15] Akiko, W. (2011). The influence of parenting on children's academic achievement comparison between the united state and Japan. Thesis submitted for partial fulfillment of master degree.

[16] Hay, I., Ashman, A. F. and Van, C. E. (2007). The influence of gender, academic achievement and non-school factors upon pre-adolescent self-concept. Educational Psychology 18 (4): 461-468.

[17] Phillipson, S., \& Phillipson, S. N. (2007). Academic expectations, belief of ability, and involvement by parents as predictors of child achievement: A cross-cultural comparison. Educational Psychology, 27 (3), 329-348.

[18] Park, Y. S. \& Kim, B. S. K. (2010). Acculturation, enculturation, parental adherence to Asian cultural values, parenting styles, and family conflict among Asian American college students. Asian American Journal of Psychology, 1 (1), 67-79.

[19] Zimmerman, B. J. (2010). Self-regulated learning and academic achievement theoretical perspectives. In B J Zimmerman \& D H Schunk (Eds.), Theories of self-regulated learning and academic achievement: An overview and analysis ( $2^{\text {nd }}$ ed., pp. 1-37). Mahwah, NJ: Lawrence Erlbaum Associates.

[20] Rubie-Davies, Christine, M. (2006). Teacher Expectations and Student Self-Perceptions: Exploring Relationships". Psychology in the Schools, 43 (5): 537-552.

[21] Marsh, H. W. \& Shavelson, R. J. (1985). Self-concept: Its multifaceted, hierarchical structure. Educational Psychologist, 20, 107-125.

[22] Paul, G., Rapport, M., \& Perreillo, L. (1991). Academic performance rating scale. School psychology review, Vol 20 No 2.

[23] Boon, H. J. (2007). Low-and high-achieving Australian secondary school students: Their parenting, motivations and academic achievement. Australian Psychologist, 42 (3), 212225 .

[24] Deepika, V. \& Asha C. (2013). Study of academic anxiety among rural and urban adolescent girls. Asian Journal of Home Science, Volume 8, Issue, 128-130.

[25] Pong, S., Johnston, J., \& Chen, V. (2010). Authoritarian parenting and Asian adolescent school performance: Insights from the US and Taiwan. International Journal of Behavioral Development, 34 (1), 62-72.

[26] Cokley, K. O., Bernard, N., Cunningham, D., \& Motoike, J. (2001). A psychometric investigation of the academic motivation scale using a United States sample. Measurement and Evaluation in Counseling and Development, 34: 109-119.

[27] Chowdhury, M. (2006). Students' personality traits and academic performance: a five-factor model perspective. College Quarterly, 9 (3). Retrieved from http://www.collegequarterly.ca/2006-vol09-num03summer/chowdhury.html.

[28] Faruk Sirin, E. (2011). Academic procrastination among undergraduates attending school of physical education and sports: Role of general procrastination, academic motivation. Educational Research and Reviews, Vol. 6 (5), pp. 447-455.

[29] Srivastava, R. \& Joshi, S. (2011). The Effect of School and Area on Academic Self-Concept and Academic Achievement of Adolescents: Retrieved from http://medind.nic.in/daa/t11/i2/daat11i2p331.pdf.

[30] Dambudzo, I. I. (2009). The relationship between learner selfconcept and achievement in secondary schools in Zimbabwe. Unpublished DEd-thesis. Pretoria: Unisa. Available from: http://hdl.handle.net/10500/2393 [Accessed: 4 April 2010].

[31] Bacon, S. C. (2011). Academic self-concept and academic achievement of African American students transitioning from urban to rural schools: Retrieved from http://ir.uiowa.edu/cgi/viewcontent.cgi?article $=2582 \&$ context $=$ etd.

[32] Liu, W. C. (1994). Academic self-concept in a streamed setting: Home environment and classroom climate factors. Unpublished M. Ed. dissertation, University of Nottingham, England.

[33] Sar Abadani Tafreshi, L. (2006). The relationship between academic achievement, Self-Esteem and Gender with Anxiety of Computer among Postgraduate of Students in University of Tabeiyat Moallem Tehran. University of Tabeiyat Moalem, Theran, Iran.

[34] Begum, J. S. and Phukan, M. (2010). Academic achievement and intelligence: A correlational study in boy and girls. Indian Psy. Rev., 56 (2): 103-106.

[35] Tiedemann, J. (2000). "Parents' gender stereotypes and teachers' beliefs as predictors of children's concept of their mathematical ability in elementary school". Journal of Educational Psychology, 92 (1): 144-151. doi:10.1037/00220663.92.1.144.ISSN 1939-2176.

[36] Chia, L. W., Wang, K. \& John, C. (2005). Academic SelfConcept: A Cross-Sectional Study of Grade and Gender Differences in a Singapore Secondary School: Retrieved from http://files.eric.ed.gov/fulltext/EJ728824.pdf.

[37] McGrew, K. (2008). Academic Ability Conception: Definition and Conceptual Background: Retrieved from http://www.iapsych.com/acmcewok/Academicabilityconceptio n.html. 